\title{
PERSONAL REFLECTIONS ON THE LIFE OF HANS JøRGEN GOTTLIEB GUNDERSEN (1943-2021)
}

\author{
JOHN F. BERTRAM ${ }^{1}$, LUIS M. CRUZ-ORIVE ${ }^{2}$, STEPHEN M. EVANS ${ }^{3}$, DALLAS M HYDE ${ }^{4}$, TERry \\ MAYHEW $^{5}$, MATTHIAS OCHS $^{6,7}$, YONG TANG $^{8}$, JENS RANDEL NYENGAARD $^{\bowtie, 3 \text { (Editor) }}$ \\ ${ }^{1}$ Department of Anatomy and Developmental Biology, Biomedicine Discovery Institute, Monash University, \\ Melbourne, Australia; ${ }^{2}$ Department of Mathematics, Statistics and Computation, Faculty of Sciences, \\ University of Cantabria, Santander, Spain; ${ }^{3}$ Core Center for Molecular Morphology, Section for Stereology \\ and Microscopy, Department of Clinical Medicine, Aarhus University, Department of Pathology, Aarhus \\ University Hospital, Aarhus, Denmark; ${ }^{4}$ School of Veterinary Medicine, University of California, Davis, \\ California, USA; ${ }^{5}$ School of Life Sciences, University of Nottingham, Nottingham, UK; ${ }^{6}$ Institute of \\ Functional Anatomy, Charité - Universitätsmedizin Berlin, Berlin, Germany; ${ }^{7}$ German Center for Lung \\ Research (DZL), Berlin, Germany; ${ }^{8}$ Department of Histology and Embryology, Chongqing Medical \\ University, China \\ e-mail: john.bertram@monash.edu, luis.cruz@unican.es,sme64@me.com,dmhyde@ucdavis.edu, \\ Terry.Mayhew@nottingham.ac.uk, matthias.ochs@charite.de,ytang062@163.com,jrnyengaard@clin.au.dk \\ (Received May 31)
}

Professor Hans Jørgen G. Gundersen MD, DMSc (1943-2021) was a pioneering stereologist whose work has inspired and influenced researchers across the world for almost half a century. He was a charismatic character and one of the founding fathers of modern stereology, whose achievements and contributions are fondly remembered below by colleagues and coworkers. It was an enormous pleasure to be in his company and although future generation will miss this opportunity, his work will live on, to inspire and influence future generations of researchers.

\section{Reflections by: John F. Bertram}

It was with great sadness that I learnt of the passing of my wonderful friend and inspiration Hans Jørgen Gundersen. While we lived and worked on opposite sides of the world, Hans Jørgen frequently travelled Down Under in the 1980s and 1990s to present and explain his new stereological methods that so revolutionised our field. I was also fortunate to meet with him at many meetings of the International Society for Stereology and the European Society for Stereology, and to visit him in Aarhus on several occasions.

I cannot overstate the impact that Hans Jørgen's contributions to stereology had on my own career. I became interested in stereology as an undergraduate student at the University of Western Australia in 1974. My subsequent $\mathrm{PhD}$ and postdoctoral training were focused on stereological studies of the lung, but by the end of this period in the mid-1980s I recognised that stereology was in need of renewal - in my research I was spending more time measuring correction factors for tissue shrinkage, section compression and section thickness than I was on the actual stereological measurements or the biological questions I was trying to answer. Stereology needed help!

In the late 1980s while at the University of Melbourne and now having commenced kidney research, I became aware of the physical and optical disector, fractionator and Cavalieri techniques developed by Hans Jørgen and his collaborators (Sterio, 1984; Gundersen et al., 1988a; Gundersen et al., 1988b) and immediately recognised their many advantages over existing stereological techniques. This was what I had been waiting for. I immediately established a stereology laboratory, publishing my first paper using these new methods reporting the numbers of glomeruli and glomerular cell types in rat kidney in 1992 (Bertram et al., 1992) and on human glomerular (nephron) number in human kidneys in 2000 (Johnson et al., 2000).

Looking back, the 1980s was the decade that more than any other influenced my research career - it was when David Barker at the University of Southampton began writing about the fetal origins of adult disease, now known as the developmental origins of health and disease (DOHaD) (Barker and Osmond,1986); when Barry Brenner at the Harvard Medical School first linked low nephron endowment with adult hypertension and chronic kidney disease (Brenner et al, 
1988); and when Hans Jørgen published many of his design-based stereological methods (Sterio, 1984; Gundersen et al., 1988a; Gundersen et al., 1988b). These landmark studies motivated me to focus my future research on glomerular number and size in animal models of DOHaD (Hoy et al, 2010) as well as in six human populations (Luyckx et al., 2013; Bertram et al.,2011; Kanzaki et al., 2017), and to examine associations of these microanatomical parameters with the development of hypertension and renal pathology. Almost all of my subsequent 150 or more stereological studies utilised the methods developed by Hans Jørgen and his collaborators.

On a more personal note, I have many fond memories of times spent in Hans Jørgen's company. He was larger than life and great fun at work and at play. He participated in a number of stereology workshops at Monash University and Lorne, most of which were organised by Dr Nigel Wreford. He also saved our bacon so to speak at the 1999 World Congress of Stereology in Melbourne when one of the Keynote Speakers failed to attend. Hans Jørgen who was already scheduled to give a Keynote quickly said, "I will give two talks if you wish"! My immediate answer was "yes please!", and he gave two wonderful talks. And speaking of Monash, Hans Jørgen is on record as saying that while staring at a wallaby through a cyclone fence at Monash he thought of the fractionator method for the first time. Perhaps the beauty of the scenery and/or the jetlag had something to do with one of his most important and useful inventions!

We owe so much to Hans Jørgen for bringing these innovative methods and approaches to science. We have lost a great man but his memory will live on for decades to come. Thank you Hans Jørgen.

\section{Reflections by: Luis M. Cruz-Orive}

\section{El camino es la Piedra. 1}

Jorge Luis Borges (1978), La rosa de Paracelso

As a local journalist put it, "Lo peor de envejecer es quedarse sin testigos." ${ }^{2}$ Hans Jørgen G. Gundersen was not a passive witness. We were about the same

\footnotetext{
1 "The path is the Stone".

2 "The worst thing of ageing is to lose witnesses".
}

age, and we shared perhaps the most exciting moments of our career.

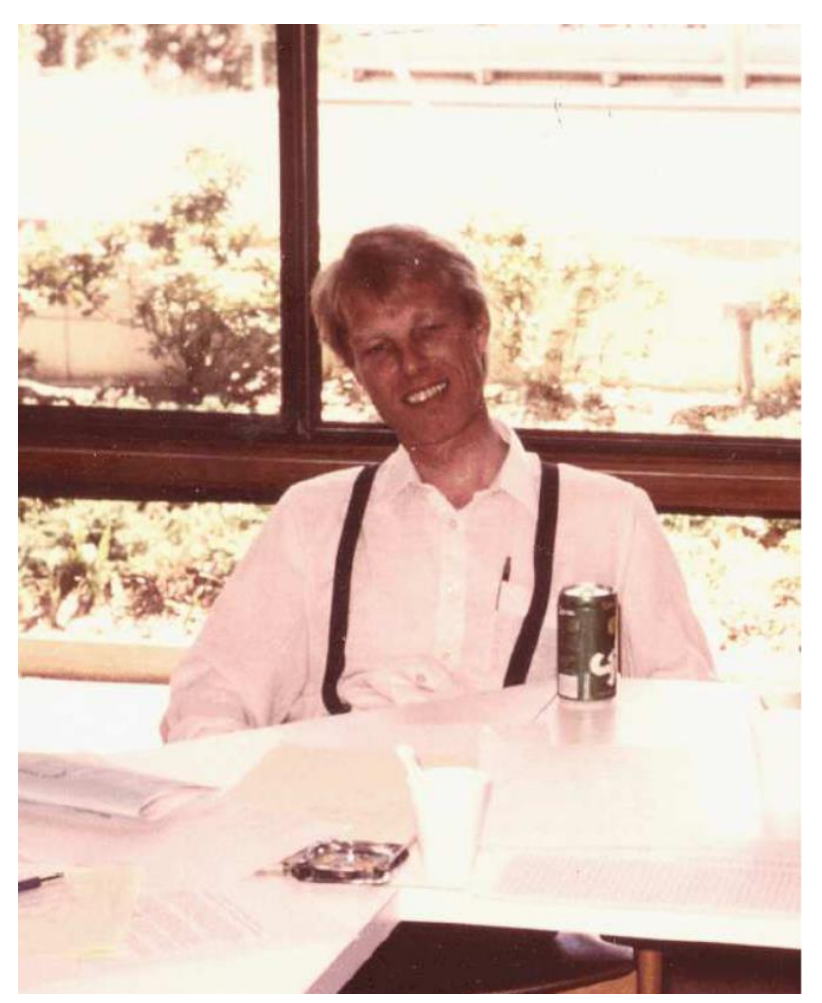

Fig. 1 Hans Jørgen G. Gundersen at the 2nd North American ISS Course in Stereology, Cedar Key, FL, USA, 25th April to 2nd May 1987.

My main recollections pertain to the International Stereology Courses we shared. Over the two decades between 1979 and 1998, we were teaching, with various staff, at 25 such courses, (19 in Europe, 3 in the USA, 1 in Canada, 1 in Australia, and 1 in Hong Kong). All the courses had a common format. The maximum number of participants was about 25 , mostly from the biomedical area. In their application form, each participant had to summarize his/her project, emphasizing the stereological aspects he/she wanted to learn at the course. A brief welcome and presentation was delivered by the local organizer the first day at 15h. The material was distributed among the participants, and each teacher received also a copy of each project summary. Thereafter, each participant had about $10-15$ min to present the project - occasionally, the presentations had to be resumed after dinner. Analogously, the last evening, and the morning of the departure day, were devoted to the discussion of the projects. Whenever possible, each participant outlined a strategy to follow back home, and the teachers tried to help with the sampling design. We learned a lot from this experience - it inspired our own work. From each course, one or two ideas would eventually develop into 
new methods; we were eager to put them to work at the budding stage.

The program, with the teachers' allocations to the different tasks, was first drafted by Hans Jørgen, and it seldom required amendments. We always gave elementary derivations for the basic equations underlying the methods. Most participants would not follow the details, but felt confident that the methods were not based on empirical approximations, but on mathematical argument. Each theory lecture was followed by an exercise, usually with real material, to illustrate the corresponding methods. Apart from the author of each exercise, other teachers assisted the participants with the details of the exercises. The working tables were large enough, and conveniently assembled into a "U" arrangement, in order to facilitate their access. At the end of the course each participant filled in a questionnaire which helped us to correct the negative aspects, and persevere on the positive ones, for the next time. The teachers' expenses were covered by modest contributions from the participants, by grants from the ISS (now ISSIA), and by local sponsors. No honoraria were accepted.

One tends to remember the first experiences best. The first ISS course I shared with Hans Jørgen was the 3rd ISS-European Stereology Course at Høyfjellshotell in Gausdal, Norway, from 23rd April to 1st May, 1979. (For most courses a site was chosen which, as we used to say in the usual humorous vein, would ensure that no participant could escape!). We counted on very few tools to teach at the time (and not too useful in retrospect). The fashionable ones were mainly spheres unfolding and Holmes effect corrections. Hans Jørgen, however, was already toying with the contributions of animals, sections and pictures to the total variation of the group mean, anticipating his seminal 'Do more less well' paper of 1981 with Ruth Østerby.

Hans Jørgen and I had met personally for the first time at the International Course in Stereological Methods organized by Ewald Weibel at the Institute of Anatomy in Bern on March 25-31, 1977, taking advantage of the fact that Roger E. Miles, the most distinguished mathematical stereologist at the time, was visiting the Institute. His lectures (based on his 1976-77 papers with his student Pamela Davy) were decisive in the subsequent development of stereology, but filling in the details for practical application took years. By the way, Hans Jørgen presented his unbiased counting rule (the 'forbidden line rule') which appeared in the $\mathrm{J}$ Microscopy a few months later. Between 1969 and 1977 he had already published 16 papers, often with Ruth Østerby, and mainly related to kidney.

Returning to Gausdal, for the aforementioned reasons the program was not dense. Thus, from 8:30 to $10 \mathrm{~h}$ we had a lecture, and from 10 to $14 \mathrm{~h}$ we had "own activities" - most people chose skiing. Work was resumed after lunch, and we had seminars after dinner. My wife Soledad accompanied me, and we brought our cross country skis with us (after all we were living in Switzerland ...). What followed aroused plenty of fun among the expert Scandinavians! Hans Jørgen remained in the hotel, and we asked him if he practised sport: "No ...", he said — "But Hans, doctors say that it is good for health!" _ "That has not been proved", he replied. Years later he invited me to his home and he showed me lots of firewood he had to split by axe, which is no light sport...

A positive aspect of Gausdal's course was the available amount of time for relaxation and exchange of ideas in the comfortable hotel lounges. Many participants wanted to count cells, or organelles, but these would not be spherical ... At least as many wanted to know "how many pictures", etc. We were really struggling trying to help them.

At the time, digitizer tablets became popular to measure planar features on sections by outlining their boundaries manually with a cursor. Hans Jørgen advocated instead the use of the much more efficient point and intersection counting for most purposes, and he was leading a real crusade on that for years. In part to convince people, he designed an exercise in which the purpose was to estimate the number and the total length of microvilli in the brush border of the cortex from a rat kidney. On a high power electron micrograph, hundreds, even thousands of microvilli transects would appear, (Fig. 6 of his paper in J Microsc 1979), and he offered to choose among counting a few transects in tiny unbiased frames, or outlining them all with a cursor. In 1981 Hans Jørgen published a paper with Morten Boysen and Albrecht Reith (who were the local organizers of the Scandinavian courses) to demonstrate the superior efficiency of point counting. Moreover, he and Eva Jensen showed in a paper of 1982 that, if the area of a disk is estimated with a uniform random square probe hitting it, then the number of corners hitting the disk yields a more precise area estimator than the disk area itself inside the square, as soon as the disk diameter exceeds the square side.

The kidney exercise was quite complete, starting with the estimation of the volume of the kidney cortex by Cavalieri, then multiplying with a nested series of 
ratios estimated on low and high power electron micrographs. The exercise was polished along the next courses, with the invaluable assistance of Ruth Østerby. At the Hong Kong Stereo '92 Course, already assisted by Bente Pakkenberg, the total estimated number of microvilli was of $3.56 \times 10^{\wedge} 11$, with a total length of $1277 \mathrm{~km}$. The exercise took about $8 \mathrm{~h}$ over 4 days. By that time the courses had matured, with most modern stereological tools already available. Stereo '92 was yet another success, and the Gausdal times were forlorn, but in the final report the following was stated: "The program was so intensive that there was in fact little time to relax".

In every Course, the main idea conveyed was that sampling is more important than measuring — or, that there will be no good science to report in the absence of a good sampling design. At some USA course, however, I recall some participants saying that, people requesting a grant to acquire an expensive image analyser, had more chance of success than those who promised good science with test systems printed on acetate sheets at a few dollars per box ...

Teachers and participants learned a lot from Hans Jørgen. His lectures were legendary - dressed in a comfortable style, in his slippers, wide trousers with suspenders, etc., his charisma, persuasive voice, and gestural expression, kept the audience trapped and absorbed. Of the many principles he established, there was one I particularly appreciate: "Simplicity is strength". The powerful stereological tools he discovered are basically very simple. When something looks complicated (e.g. the unfolding algorithms for spheres and spheroids) then simpler alternatives are likely to exist (e.g. the disector, the local stereology estimators, etc.), but discovering them may take much longer. When an ordinary mortal obtains a potentially useful mathematical formula, the latter may stay there sine die. If Hans Jørgen saw it, however, then the outcome could be very different. He was probably the person with the sharpest intuition I have ever met - he had a special gift to perceive, before anyone else, what was going to be important, and what not. I conceived the idea of the selector in 1985 at the 9th ISS Course in S-Gothenburg. In the corresponding paper of 1987, Eq. (B.2), based on a well known result of elementary calculus, looks identical to the nucleator equation, but I considered only the case in which the rays emanate from a uniform random point inside a particle. When Hans Jørgen saw it (we used to exchange ideas and preprints) he thought: why not a fixed point instead, e.g. an observable nucleolus within a cell? On November the 7 th, 1986, he sent me a preprint entitled:
The nucleator: the unbiased stereological estimation of mean sizes and number of arbitrary cells on one or a few sections of unknown thickness. At the bottom of the title page he handwrote: “(PS. I 'saw' this idea 18:59, 29/10-86, and just managed to finish the ms. and submit it to the Editor in 6.84 days. There are accordingly - a few misprints!)". At the top he handwrote a kind dedication, and he also typed: "J. Microsc., subm. 5th Nov.-86. Short technical note.”

For Hans Jørgen the ISS courses were not enough: he travelled round the world delivering seminars and participating in many research projects. He was very strong, he could endure almost any conditions, and was able to work at airports, or almost anywhere. Apart from his professional commitment, he was warm and sensitive to people, and empathic with anyone's personal problems. His publications are countless, but he referred to published papers as "paper". The exciting part of the job was not to reach the publishing stage, but the itinerary traversed to arrive at it, then immediately looking at the next. The exciting thing would not be the nucleator paper, but the aforementioned 6.84 days. The goal was not the Stone that turns all elements into gold: The path was the Stone.

\section{Reflections by: Stephen M. Evans}

It was the late eighties and my $\mathrm{PhD}$ supervisor, Prof. Vyv Howard had arranged for me to spend a couple of weeks in Hans Jørgen's lab at Aarhus University. A few weeks became most of my $\mathrm{PhD}$ and a stint as a postdoc. Hans Jørgen had created a magical place to work, staffed by researchers eager to implement the latest stereological techniques, supported by technicians who were experts in the practical methods for stereology, visiting stereological luminaries, a close partnership with the mathematics department and Hans Jørgen at probably his most productive; full of passion, enthusiasm and creativity for stereology. He was a trailblazer who liked to push the limits of himself, other people, technology and deadlines.

He negotiated with the editor of APMIS to extend yet another deadline for a review article from the Friday afternoon until the following Monday. However this was the weekend of a major family event, his daughter's confirmation. He dedicated the days to his family and at night wrote the review. Monday morning the whole lab proofread the review article and Hans Jørgen had a discussion with every individual about their comments. Both the article (Gundersen et al., 1988a) and the confirmation were great successes. 
He asked me to prepare some neocortical tissue $25 \mu \mathrm{m}$ thick glycolmethacrylate sections for Prof. Eva Vedel Jensen to investigate spatial distribution patterns of neurons and glia. When asked if I could make them thicker I replied, maybe but I may damage the lab's most expensive microtome. He explained in research we have to push back frontiers, that I was not maliciously damaging the equipment and that's why we have service contracts. The section thickness was doubled but the microtome did need a service.

Hans Jørgen loved to discuss his latest ideas with colleagues and the more informal the situation the better the discussion. Over a post lunch drink(s) with my PhD supervisor at Hans Jørgen's house where we were discussing what I was doing for my $\mathrm{PhD}$ and Hans Jørgen was explaining his latest invention, the use of the "Nucleator", (Gundersen 1988). to estimate number in a defined space, (Bagger et al. 1993). He had been inspired by a diagram in Prof. Luis CruzOrive's "Selector" paper, (Cruz-Orive 1987) to develop a series of estimators for particle volume, surface area and number. It was the first time that particle number could be estimated using a length measurement to estimate the probability of an event occurring. I naively pointed out that this was also why he had asked me to make the thick sections for Eva and so began an adventure in spatial distributions and $\mathrm{K}$ functions which he very generously attributed as my idea in the second APMIS review, (Gundersen et al., 1988b).

For many years whilst he developed his research career he worked as an on-call family doctor. He was well respected by his colleagues and loved by his patients. Although he was not an academic clinician working in an "Ivory Tower" he was very competent doctor. When I left his lab to start studying medicine he gave me an inciteful piece of advice: 90\% of the patients you will see will get better no matter what you do, of the rest some will get worse and some will die and you have to come to terms with that. But there are 1 or $2 \%$ who you can be sure did get better because of you and that makes the job worthwhile.

Whilst the percentages could be debated this advice has helped in injecting some pragmatism when discussing the latest "wonder drug" in drug development meetings from big pharma to small "biotechs". More significantly in the early hours of the morning in a busy Emergency Room which has descended from bad to worse to chaos and one of my junior doctors was close to giving up, I tell them of my friend and mentor, of his advice and maybe the next patient is the 1 or $2 \%$. It has saved a few medical careers and more importantly a few lives.
Hans Jørgen G. Gundersen pioneering stereologist, inspirational leader, clinician, dedicated family man and friend.

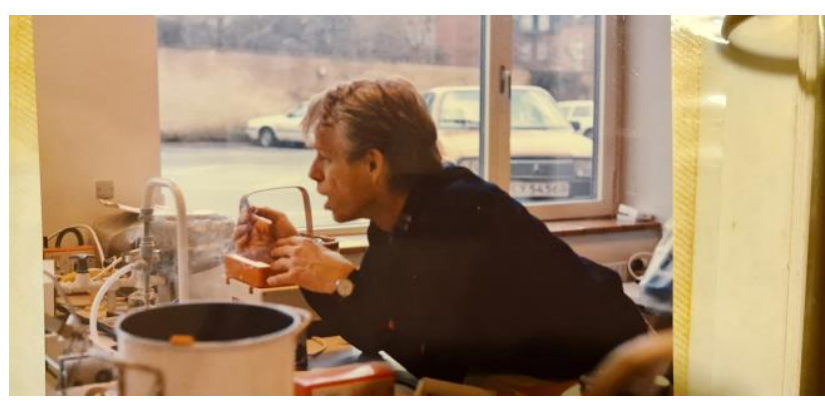

Fig. 2. Hans Jorgen G. Gundersen in his laboratory at Aarhus University of, Spring 1988.

\section{Reflections by: Dallas M Hyde}

The first time I met Hans was in September 1979 at the Fifth International Congress for Stereology in Salzburg. He presented a paper on optimizing sampling efficiency of stereological studies. In presenting the paper he was dressed in red suspenders and boldly told the audience that we were sampling too much within tissues and not including enough animals which he clearly showed with convincing data. It was to be his gift to science, seeing the forest instead of just the trees, the big unifying concepts instead of just the details. During the discussion of the paper, Ewald Weibel posed the question, 'then you are telling us to do more less well'. Hans loved the question and used the phrase in his publication in the Journal of Microscopy a year latter titled Optimizing Sampling Efficiency of Stereological Studies in Biology: or 'Do More Less Well!'

The next time I met Hans was at the First American Congress on Stereology in Davis, California in 1981 that I organized with Bob DeHoff. At a reception I discussed my work to estimate the mean caliper diameter of nuclei using computer reconstruction for the estimation of number per volume. Hans' critique of my approach was the small sample size of nuclei used for the estimate of mean caliper diameter. He told me he was working on an approach using serial sections that estimated the height of structures along the section direction, which included a robust sample size. He published his work in the Journal of Microscopy in 1984 titled The Unbiased Estimation of Numbers and Sizes of Arbitrary Particles Using the Disector under the pen name D C Sterio, an anagram of disector. My first reaction to reading his paper was 'why didn't I see this as I was grappling with the estimation of number in 
volume'. This was Hans' gift, seeing clearly the stereological unifying approach while others missed it.

One of the Hans' greatest contributions was his generosity to share his knowledge with others. He and his Danish colleagues taught innumerable stereology courses across the world over his career. I was fortunate to participate in some of the courses. A course that I helped organize in November 1999 was held at the Stanford Sierra Camp at Fallen Leaf Lake near Lake Tahoe. At the opening reception, Hans and I were standing next to a fireplace and put our beers on the mantle. We were discussing using the Euler number to estimate the number of alveoli in the lung. I explained how alveoli were like clusters of grapes in all orientations and that I had tried using serial reconstructions of alveoli and a tangent count to estimate number, but found it too laborious. As we picked up our beers he looked at the mantle and saw two rings left from the condensation and said 'we'll count the rings'. He meant the alveolar opening rings, a unique countable feature of each alveolus. Collaborations with Hans on this approach resulted in publications in 2004, one with me estimating alveolar numbers in rats and monkeys and the other in humans with Matthias Ochs. This approach was adopted in 2010 in 'Standards for Quantitative Assessment of Lung Structure' by a publication of the Joint Task Force of the American Thoracic and European Thoracic Societies. Hans also collaborated with various commercial entities to enhance the ease of use of his stereological approaches. Commercial systems that import whole slide scan images in serial stacks, samples them, and analyzes them efficiently which enables investigators to use the unbiased stereological methods with confidence and efficiency. We owe an unimaginable debt to Hans for his creative genius, engaging personality and generous mentorship and have been fortunate to have known him.

\section{Reflections by: Terry Mayhew}

During our lives we are fortunate to meet those who, like our parents and schoolteachers, offer critical advice and guidance or stimulate our interest in certain subjects or disciplines. Still others exert even greater influence because of their own exceptional talents and achieve exalted status by being there at milestone moments. For me, Hans Jørgen was one such individual.

We first met in 1975 when, as early-career stereologists, both of us were invited speakers at a

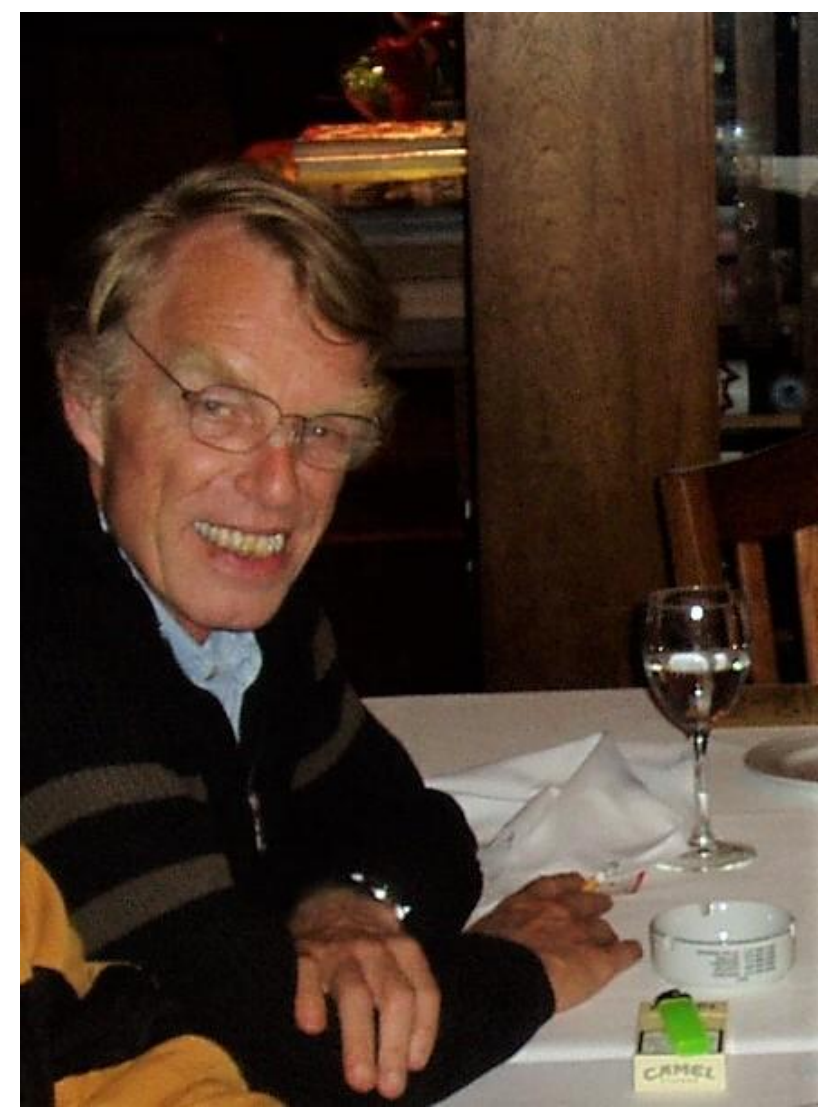

Fig. 3. Hans Jфrgen, Brazil 2005.

meeting held at the Wenner-Gren Institute in Stockholm. At the time, he was developing (with Ruth Østerby) stereological methods for estimating the true thicknesses of biological membranes from their apparent thicknesses as seen on microscopical thin sections. He delivered an excellent talk but appeared rather diffident during subsequent questioning. Little did we know that his confidence would quickly grow and that he would soon shine a bright light of scientific rigour on many aspects of the development and application of stereological methods. He has been a source of admiration and inspiration to me and so many others.

In 1977, he took his first significant step into the light and began his transformation from an explorer to a pioneer. In that year, he published a paper on the unbiased estimation of numbers of arbitrary profiles. During my PhD researches, I had used a haemocytometer chamber to count leucocytes in peritoneal exudates but was unaware that the accepted counting rule was not, in general, unbiased. Hans Jørgen identified the problem and introduced us to unbiased counting rules in stereology based on associated points and the forbidden line counting frame. The stage was being prepared for unbiased particle counting in 3D: counting 
on the basis of presence alone and untainted by systematic errors associated with particle size and shape.

After 1975, we started to meet regularly while teaching together on numerous international courses between 1978 (Norway) and 2010 (Brazil). I cherish memories of that shared teaching and learning. When the Norwegian courses for stereology and morphometry were initiated by Albrecht Reith in 1978, Hans Jørgen, Luis Cruz-Orive and myself were recruited as the principal course teachers. We divided topics between us and, up until 1981, I had covered lectures and practical classes on particle number estimation. I often began my introductory lecture with an anecdote about 'perfectly spherical chickens' in order to emphasise that the current methods were all assumption-based. Before the following year's course, Hans Jørgen approached me to ask if I would deal with surface estimation so that he could cover number estimation. He was obviously eager and excited about doing so and I was intrigued. So, of course, I agreed. It was only during his lecture that I understood the reason for his eagerness and excitement. I sat open-mouthed while he presented what was to become the physical disector method.

For me, that lecture was the revelatory and seminal moment in stereology after which models were discarded and design-based methods came to 'rule the roost' (forgive the pun!). I am reminded still of the quote by Isaac Newton: "I seem to have been only like a boy playing on the sea-shore and diverting myself in now and then finding a smoother pebble or a prettier shell than ordinary, whilst the great ocean of truth lay all undiscovered before me.".

Following his lecture, I asked how the idea for the unbiased counting rules was born. He has been asked this question many times since and, over the years, had given different replies. His explanation to me is the one I like best. He said that, whilst in Australia, he was sitting in front of a large picture window through which he could see lots of kangaroos and realised that he could count them within the frame of the window by using an associated point rule (i.e. the tips of their snouts). This exemplified his sense of humour and his playfulness as, indeed, did his pseudonym (DC Sterio) for the disector paper, published in 1984. He went on to lead the way in developing and applying design-based methods. I need mention but a few terms: vertical sectioning, the fractionator, isector, nucleator, proportionator, weighted mean volumes.

In 1991, I was about to leave the University of Aberdeen to take up a new post at the University of
Nottingham. I was asked to invite 'anyone you like from anywhere in the world' to come to Aberdeen and deliver a lecture at a symposium arranged to mark my departure. There was only one person who I wanted and that was Hans Jørgen. By this time, he had developed so many pioneering methods. He came and spoke to an audience of biochemists, physiologists, pharmacologists, morphologists and others about those methods. In my introduction to his lecture, I compared his revolutionary discoveries, particularly the disector method, with those made by Albert Einstein in 1905 which transformed modern Physics. I hosted his stay in Aberdeen and we enjoyed a few days together at my home where, with a bottle of Danish akvavit which I had bought especially, we made numerous toasts to Stereology and Mor Danmark!

In 1994, he received the first of numerous awards. It was the Novo Nordisk Prize, awarded 'for his great, original and internationally recognized efforts in the field of stereology'. So proud was he that he wrote to his friends to share the good news. On 24th January that year, he sent me a copy of the Prize brochure outlining his achievement accompanied by a letter which reads "Dear Terry, $10^{9}$ thanks! I am, of course, uninhibited in my joy, pride and happiness on behalf of Stereology. Personally, I can only handle the situation by sharing the publicity and the joyous moments with all of you whom together have contributed the most.". That is another measure of the Man.

In 2009, I was diagnosed with bowel cancer but was treated successfully by surgery and adjuvant chemotherapy. Early in December 2020, I heard the tragic news that he was terminally ill and being cared for by his daughters on the Danish island of Møn and immediately emailed him to express my sympathies and my hope that his treatment would do some good. At the same time, I thanked him for his contributions to stereology and for repeatedly reinforcing my own confidence in the value and power of its tools.

To me, Hans Jørgen will always be an individual of exceptional stature and influence who I was very lucky to have met and befriended. If we are lucky, we all shine brightly for a while and, though the light eventually fades, it never dies completely. Indeed, for those who shine the brightest, the fading takes that much longer. Tak for alt min ven. Tak for alt.

\section{Reflections by: Matthias Ochs}

Why does one become a scientist? Curiosity is certainly important, combined with the desire for intellectual freedom. But what is most important to 
succeed in science? Perhaps to meet the right people at the right time, people that become mentors and sources of inspiration and motivation. People that broaden our horizon and change our way of thinking and acting. To me, Hans Jørgen Gundersen was such a person.

In 1994, after my medical studies, I started working at the Center of Anatomy at the University of Göttingen, because at that time I already knew that I wanted to become an anatomist, although this was an uncertain career path compared to clinical subjects. My doctoral thesis dealt with ultrastructural changes in alveolar epithelial type II cells during ischemic storage of lungs for transplantation. This, of course, involved stereology at the electron microscopic level. I got away with some basic point and intersection counting based on methods established by Ewald Weibel, but felt that for my future work more sophisticated techniques were needed to better characterize the secretory organelles of these cells, the surfactant-storing lamellar bodies. How do type II cells handle their intracellular surfactant content under different physiological and pathological conditions? This would require knowledge about type II cell number per lung and mean cell size, as well as lamellar body number per cell, their mean volume and their volume distribution. The methods necessary to obtain such data (disector, nucleator/rotator, pointsampled intercepts) were available at that time, but had not been applied to the lung, in particular the disector at the EM level. All these revolutionary methods came from one place - Aarhus. And they were all developed thanks to the ingenuity of one man - Hans Jørgen Gundersen.

An opportunity for me to get first-hand experience in these new stereological methods was an EMBO course on "Quantitative immunoelectron microscopy", organized by John Lucocq in Dundee in 1995. Here I met Terry Mayhew and Jens Nyengaard, who taught the stereology part of the course, for the first time. I kept in contact with Jens about my planned research projects, and he invited me to come to Aarhus to discuss these further. It must have been in late 1995 when I first visited the Stereological Research Laboratory on the beautiful University campus. I vaguely remember that I noticed a piece of paper hanging on the lab wall before entering Hans Jørgen's office to meet him for the first time. This piece of paper stated something like that if you slice Mick Jagger and David Bowie for a Cavalieri estimator, take a sample fraction of $1 / 2$ of each and glue it together, you get Hans Jørgen. Was I about to talk to the rock star of stereology? Indeed, the morphological similarities were obvious. Hans Jørgen's office door was, as always, open. He was sitting at his desk, surrounded by paper all around him. Actually it was hard to see him through the dense smoke. Hans Jørgen impressed me from the very first moment, because of his great interest and enthusiasm for my project and his immediate understanding of the problem - and also his explanation of its solution. Hans Jørgen showed me the way I should go in terms of lung stereology, and since then I have tried my best to do so. His constant support helped me enormously through times when I felt insecure whether I would ever reach a tenured position. In retrospect, the fact that I did clearly has a lot to do with Hans Jørgen.

The best approach to learn stereology in a way that it can be integrated in one's practical work (in case you are not blessed with having an experienced stereologist on campus) is to attend a stereology course. Such courses were established in the 1970ies, and Hans Jørgen became their spiritus rector. I participated in the $15^{\text {th }}$ European Stereology Course of the ISS in Skørping in 1997. I liked the way the course was organized, with a mix of lectures and practical exercises, and with intense interactions between teachers (besides Hans Jørgen, the faculty included Luis Cruz-Orive, Bente Pakkenberg, Jens Nyengaard, Karsten Nielsen and Thomas Bendtsen) and participants and ample time for discussing projects individually. When there was need for organizing the 18th European Stereology Course in 2000 within shorttime notice, Hans Jørgen and Jens suggested that I should volunteer. And so I did and found a place in Goseplack near Göttingen. This is how I got involved as a stereology teacher. Since then, I had the pleasure of teaching at many more stereology courses all over the world, several of them together with Hans Jørgen. I always found this extremely rewarding, because through the interactions with the participants, one becomes exposed to so many fascinating biological and medical projects to which proper stereology can make a valuable contribution. Beyond that, the elegant basic principles of stereology that are covered during these courses, in particular the inherent unbiasedness of design-based stereology, teaches everybody the grassroots of good scientific practice in general. In that sense, stereology makes better scientists.

When I entered the field of lung stereology, the basic characterization of lung structure had been established by Ewald Weibel, in particular estimates of subcompartment volumes, alveolar and capillary surface areas, blood air barrier thickness and, derived from that, lung diffusion capacity (for historic review of Ewald Weibel's work, see Ochs; 2020). But one 
important parameter was missing: alveolar number. Earlier estimates by Weibel relied on assumptions about alveolar shape and size distribution as well as the ability to recognize alveoli unambiguously in single histological sections. This model-based approach was considered obsolete, so the field was in need for a design-based alternative. Although of less relevance for overall function, unbiased estimates of alveolar number are highly important for mechanistically understanding lung development, regeneration and pathology, e.g. bronchopulmonary dysplasia or emphysema. And although the disector method was published in 1984 (by D.C. Sterio, as we know), it took another 20 years to make it practicable for counting lung alveoli. Due to their openings into alveolar ducts, alveoli are incomplete and connected "particles" that cannot be counted in disectors in the ordinary way. The solution came, of course, from Hans Jørgen when he discussed this with Dallas Hyde at a stereology course in the US. Interestingly, the seemingly disadvantageous architecture of alveoli was eventually used to solve this long-standing problem in lung biology. Based on the topological properties of the network of alveolar openings, the Euler-Poincaré characteristic (or, in short, the Euler number) was estimated using physical dissectors at the light microscopic level. So, in the end, alveolar openings became the counting event for disector-based estimation of alveolar number (Hyde et al., 2004). Hans Jørgen kindly shared this method with me before it was published. I had a set of well-suited human lungs available. They came from young organ donors in cases of unilateral lung transplantation when their contralateral donor lung could not be matched by Eurotransplant to a suitable recipient. With a lot of practical help from Jens Nyengaard, we estimated the number of alveoli in the human lung and published our data, with Hans Jørgen as senior author, in a prestigious lung journal (Ochs et al., 2004a). Then I went on and applied this approach, together with the methods for type II cells and lamellar bodies that we had already established, to different animal models of lung disease, e.g. for the quantitative phenotype characterization of gene-manipulated mouse models of surfactant metabolism. On the first of these papers, I offered coauthorship to Hans Jørgen, but he refused because he felt that he had given away this method to the world. Instead he requested that I use his institutional affiliation, which I proudly did (Ochs et al., 2004b).

After my first visit to Aarhus in 1995, I returned many times to meet Hans Jørgen and Jens. I always felt welcome, and I always took a lot of new ideas back home. The last time I saw Hans Jørgen was at the
International Congress for Stereology and Image Analysis in Aarhus in May 2019, the last scientific meeting he attended. At the beginning of the last session, where my talk was scheduled, he said farewell to me. But until then, there was more joint work on lung stereology to come. Our interactions continued, no matter where my way in academia had led me. Still in Göttingen, I met a young medical student, Juliane Knust, who wanted to do her doctoral thesis with me. She did the practical part of her work together with Hans Jørgen and Jens in their lab in Aarhus. Beyond the scientific output, a detailed description of state-ofthe-art mouse lung stereology (Knust et al., 2009), the impact of her stay was much more profound. It is fair to say that she returned as a different person, matured both scientifically and personally - clearly an effect of the special Stereological Research Laboratory climate in Aarhus.

In a subsequent collaboration, Hans Jørgen even went one step further, and Dvoralai Wulfsohn bravely mastered the challenge. This challenge was to establish a method for estimating the number of "functional units" of ventilation in the lung. This is not the single alveolus, but the complex of connected alveoli distal to the transition from the last air-conducting to the first gas-exchanging (i.e. alveoli-containing) branching generation along the airway tree. This unit is termed the acinus. Due to the presence (e.g. in humans) or absence (e.g. in mice) of respiratory bronchioles which are partly alveolated, considerable species differences exist with respect to the size of acini and the number of branching generations in a single acinus. However, these respiratory bronchioles contribute very little to gas exchange. As an alternative to the acini, "ventilatory units" have been suggested, defined as the units of lung parenchyma distal to a single bronchiolealveolar duct junction (BADJ). No matter whether the last generation of bronchioles contains some alveoli or not, all branching generations within such a ventilatory unit are completely alveolated, thus eliminating difficulties arising from species differences. Moreover, the BADJ is unambiguously present in histological sections, characterized by an abrupt transition from a ciliated cuboidal bronchiolar epithelium to a squamous alveolar epithelium, thus making it an ideal candidate for counting topological changes in physical disectors. In practice, the method consists of the combination of two estimators, namely an estimator of the Euler number of all openings of the bronchial tree and an estimator derived from direct counts of topological changes at BADJs. Interestingly, a potential source of bias inherent to each one of them is eliminated when they are combined. The final paper is, both 
theoretically and practically, not for the faint-hearted, and describes one of the most demanding methods in biomedical stereology (Wulfsohn et al., 2010). After more than 10 years, it still awaits its second application. Most likely this second application will not be based on light microscopy, but on 3D datasets using non-descructive imaging methods such as micro-CT (Knudsen et al., 2021).

The 2004 paper on the number of alveoli in the human lung and the expertise I gained in lung stereology became vital for my future career. It significantly contributed to earning me a position at the Institute of Anatomy at the University of Bern in 2005 (my first tenured position!). For decades, this institute, formerly directed by Ewald Weibel, was considered the world center of lung stereology. I felt the obligation of fusing "traditional" and "modern" stereology at this special place. So I took over the organization of the annual stereology courses and gave it a new schedule and direction, based on the ISS courses I was familiar with, with some lab practicals added. Hans Jørgen (during the first few years) and Jens (still ongoing) became regular teachers. I was aware that inviting Aarhus stereologists to Bern could lead to diplomatic trouble. Hans Jørgen and Ewald, undisputably the two giants of biomedical stereology, had a very special relationship, not without personal difficulties. They clearly respected each other, but they were so different as characters that you could feel the tension when they were present in the same room. At the occasion of one of the Bern stereology courses, I think it must have been in 2008, Ewald came by around noon and invited Hans Jørgen for lunch. Whatever they discussed besides stereology, surprisingly they returned with an idea for a joint project they wanted to discuss with me. This project addressed a disputed parameter in lung stereology which had caused (and still can cause) fierce discussions in the community: the mean linear intercept length (MLI) of the gas-exchanging (i.e. alveolicontaining) lung parenchyma. What MLI actually measures is the mean free wall to wall diffusion distance for oxygen molecules within the alveolar region of the lung. What it does not measure is alveolar size. Moreover, MLI critically depends on the state of lung inflation and is thus subject to the well-known "reference trap". Therefore, MLI is not useful as the sole parameter to describe emphysematous alterations in the lung, in particular because much better alternatives are available (Ochs, 2014). In the paper that turned out of this collaboration, we tried to explain what MLI means (and not means), and how it can be estimated properly using stereology (and not automated image analysis). Unbiased estimates are possible either directly (length measurements, taking edge effects into account) or indirectly (via point and intersection counting as a V/S ratio). Interestingly, our paper (Knudsen et al., 2010) is well-cited - but mostly for the wrong reasons. Lung researchers abuse it to justify their quick and dirty MLI data as measures of alveolar size in emphysema models although in that paper we clearly explain why they shouldn't. Nevertheless, after knowing each other for more than 30 years, this became the only scientific paper that Hans Jørgen and Ewald published together - at the age of 67 and 81, respectively. In retrospect, my role in this scenario was merely the animal tamer.

The stereological methods for characterizing lung and surfactant structure that I was able to establish with the invaluable support by Jens and Hans Jørgen became daily routine in our lab. Moreover, they also became an integral part of an official research policy statement of the American Thoracic Society and the European Respiratory Society on "Standards for quantitative assessment of lung structure". This project went over several years and meetings. Hans Jørgen was an important member of the committee, and I remember well our long phone calls meticulously discussing the drafts. With the publication of this document in 2010, we officialized stereology for the lung community (Hsia et al., 2010).

As a person, Hans Jørgen Gundersen was truely unique. Thinking of him, the first memories that come to mind are his big smile and laughter, and his neverending enthusiasm for other people's ideas. Every conversation with him was a great motivation to tackle and sharpen the next project. Open-mindedness was the core of his personality and the secret of his scientific success. Boundaries, hierarchies, formalities? He couldn't care less. Hans Jørgen was a most unconventional man, gifted with a deep understanding of relevant medical problems and complex biological structures as well as mathematical principles. By this, he was able to connect different worlds usually separated by borders of scientific language and thinking that he could easily cross. Hans Jørgen was also an extremely charismatic teacher. He could explain even the most complex stereological relationships, impossible to understand for a nonmathematician when reading the theoretical papers published in the Journal of Microscopy, in a very simple and elegant way. For my own teaching, I gratefully took over many of his everyday examples that opened my eyes for the beauty of stereology.

What is science all about in the end? Perhaps increasing knowledge - or decreasing ignorance. But, 
on a personal level, it is most of all fun. And a particular joy are the encounters and friendships that arise from a life in science. The biomedical stereology community misses its leading figure and greatest innovator. Lung stereology would not be the same without Hans Jørgen Gundersen. His creative genius changed the field forever. My scientific career and my way of scientific thinking would not be the same without Hans Jørgen Gundersen. I am deeply grateful to have met him and to have learned from him.

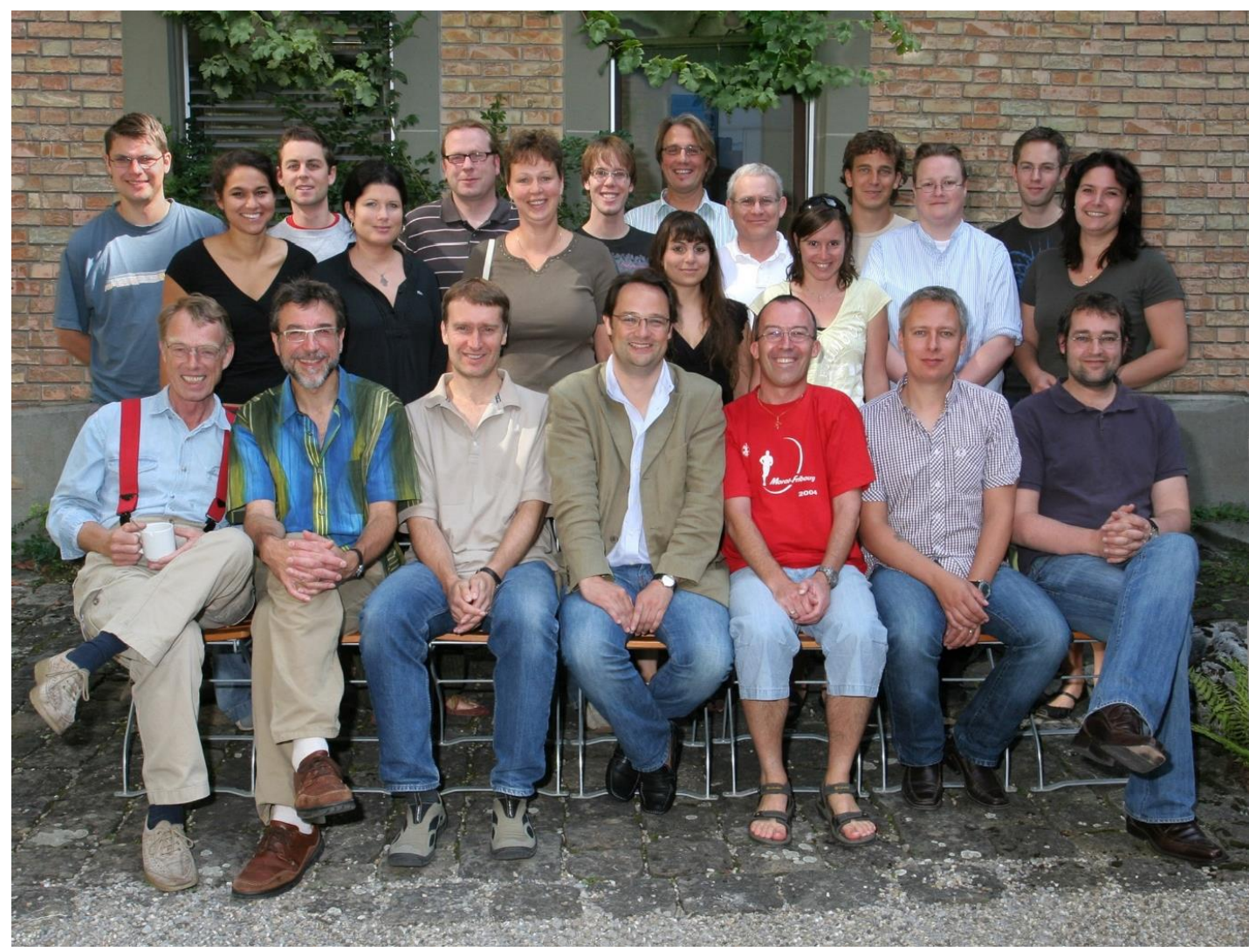

Fig. 4. Hans Jorgen Gundersen together with faculty and participants at the Stereology Course in Bern in 2008. He clearly stands out, not only because of red suspenders and coffee mug.

\section{Reflections by: Yong Tang}

I went to the Stereological Research Laboratory, Aarhus University, Denmark as a visiting scholar on March 1, 1994. After finishing one year study, I became a Ph.D student in the Lab. under the guidance of Hans Jorgen and Jens. I greatly appreciate my Ph.D supervisor, Hans Jorgen, for teaching me how to do science and how to deal with my life! I went to his always open and smoke-filled office quite often to discuss my research projects and talk about life and philosophy etc. Sometimes, we started talking around 5:00 pm, and finished at 9:00 pm. He generously shared his scientific knowledge and his life experience with me, and the time we spent together was most instructive, educational and enjoyable. As a result of the $\mathrm{Ph}$.D. training I undertook with Hans Jorgen, I learnt how to apply the modern stereological methods in neuroscience studies. When I worked in Northwestern University
Medical School, UCLA Medical School and Mount Sinai Medical Center after finishing my Ph.D. study, I guided the stereological design in their projects. After coming back to China in 2004, I arranged stereological courses for the postgraduate students for some universities in China. My team has been using the modern stereological methods in the projects of aging, Alzheimer's disease and depression. Until now, I have recruited nearly 100 Master students, Ph.D.'s and Postdoctoral students. I taught each of them the stereological methods, and they used the stereological methods in their projects. Until now, I have had more than 30 successful research applications, including ten grants from National Natural Science of China. The stereological methods have been used in each application. I have been the vice president of the Chinese Society for Stereology and the vice president of the International Society for Stereology for two terms. The training from Hans Jorgen has been the foundation of my 
research career, and therefore I believe that Hans Jorgen changed my life.

As the greatest founder of the modern stereology, Hans Jorgen greatly supported the development of stereology in China. On September 3-7, 1991, Hans Jorgen held $4 \frac{1}{2}$ day stereological course in the West China University of Medical Sciences. On July, 1994, Hans Jorgen delivered an academic lecture in the West China University of Medical Sciences. On October, 2011, he was the Honor President of 13th International Conference for Stereology in Beijing, and he gave an invited lecture.

Personally, I considered Hans Jorgen as my best friend. During my early interactions with HJGG there were a series of unfortunate events that caused me great embarrassment but HJGG took it with good grace and humor. At a 1994 stereological course in Stockholm, I yawned extremely loudly during his lecture, so that everyone in the classroom heard it very clearly. In 1995, when I suffered from a gallbladder stone, he drove me to my private doctor and when I stepped out of his car, I broke the car door. When I went to Denmark, he lent me his new bicycle to me. When I returned it to him after 3 years, the bicycle was quite damaged. He never blamed me for any of these mistakes. Before I left Denmark, he told me that everybody makes mistakes every day, except for liars or vegetative patients. When I suffered from a gallbladder stone, he visited me at Aarhus University Hospital before I had the operation. At the beginning of my Ph.D. study, there was no financial support for me, and he used the money from his Novo Nordisk prize to pay my living expenses for a few months. From 1995 to 1998, he paid my English teacher fee - every week I spoke with an American English teacher for one hour. Due to his great reputation in stereology and the longterm cooperation with Prof. Yuri Geinisman in the Northwestern University, USA, Prof. Geinisman kept his postdoctoral position for me for three years until I finished my Ph.D. study in 1998. When I applied for my permanent resident visa of the United States, Hans Jorgen provided a very strong support letter for my application. When my son graduated from Harvard University in 2009 , he called my family to celebrate my son's graduation just, as we had finished my son's graduation ceremony. Before my son graduated from his college, Hans Jorgen sent gifts to my son and my family, and after the gifts were returned three times, we finally got them. For his birthday and at Christmas, we have had very long phone conversations every year. At the 13th
International Conference for Stereology in Beijing, my two postgraduate students and I hosted his stay in Beijing, and we enjoyed some wonderful days together in Beijing.

I am happy to have so many good memories of Hans Jorgen, and he will definitely stay with me forever!

\section{REFERENCES}

Bagger PV, Bang L, Christiansen MD, Gundersen HJ, Mortensen L. Total number of particles in a bounded region estimated directly with the nucleator: granulosa cell number in ovarian follicles. Am J Obstet Gynecol. 1993 Feb;168(2):724-31.

Barker D.J.P., C. Osmond. (1986) Infant mortality, childhood nutrition and ischaemic heart disease in England and Wales. Lancet 327:1077-1081.

Bertram J.F., M. Soosaipillai, S.D. Ricardo, G.B. Ryan. (1992) Total numbers of glomeruli and individual glomerular cell types in the normal rat kidney. Cell Tissue Res. 270: 37-45.

Bertram J.F., R.N. Douglas-Denton, B. Diouf, M.D. Hughson and W.E. Hoy. (2011) Human nephron number: implications for health and disease. Ped. Nephrol. 26:1529-1533.

Brenner B.M., D.I. Garcia, S. Anderson. (1988) Glomeruli and blood pressure: less of one, more the other? Am J Hypertens 1: 335-347.

Cruz-Orive LM. Particle number can be estimated using a disector of unknown thickness: the selector. J Microsc. 1987 Feb;145(Pt 2):121-42.

Gundersen HJ. The nucleator. J Microsc. 1988 Jul;151(Pt 1):3-21.

Gundersen H.J.G., T.F. Bendtsen, L. Korbo, N. Marcussen, A. Moller, K. Nielsen, J.R. Nyengaard, B. Pakkenberg, F.B. Sorensen, A. Vesterby, M.J. West. (1988a) Some new, simple and efficient stereological methods and their use in pathological research and diagnosis. APMIS 96:379-394.

Gundersen H.J.G., P. Bagger, T.F. Bendtsen, S.M. Evans, L. Korbo, N. Marcussen, A. Moller, K. Nielsen, J.R. Nyengaard, B. Pakkenberg, F.B. Sorensen, A. Vesterby, M.J. West. (1988b) The new stereological tools: disector, fractionator, nucleator and point sampled intercepts and their use in pathological research and diagnosis. APMIS 96:857-881.

Hoy W.E., J.R. Ingelfinger, S. Hallan, MD Hughson, SA Mott, JF Bertram. (2010)The early development 
of the kidney and implications for future health. J Dev Orig Health Dis 1:216-233.

Hsia CCW, Hyde DM, Ochs M, Weibel ER. (2010) An official research policy statement of the American Thoracic Society / European Respiratory Society: Standards for quantitative assessment of lung structure. Am J Respir Crit Care Med 181:394-418.

Hyde DM, Tyler NK, Putney LF, Singh P, Gundersen HJG. (2004) Total number and mean size of alveoli in mammalian lung estimated using fractionator sampling and unbiased estimates of the Euler characteristic of alveolar openings. Anat Rec 277:216- 226.

Johnson K.J., N.G. Wreford, W.E. Hoy, J.F. Bertram. (2000) Estimating total glomerular number in human kidneys with a physical disector/fractionator combination. Image Analysis \& Stereology 19: 105-108.

Kanzaki G., V.G. Puelles, L.A. Cullen-McEwen, W.E. Hoy, Y. Okabayashi, N. Tsuboi, A. Shimizu, K.M. Denton, M.D. Hughson T. Yokoo and J.F. Bertram. (2017) New insights on glomerular hyperfiltration: a Japanese autopsy study. J. Clin. Invest. Insight 2(19) pii: 94334. doi: 10.1172/jci.insight.94334.

Knudsen L, Weibel ER, Gundersen HJG, Weinstein FV, Ochs M. (2010) Assessment of airspace size characteristics by intercept (chord) measurement: an accurate and efficient stereological approach. J Appl Physiol 108:412-421.

Knudsen L, Brandenberger C, Ochs M. (2021) Stereology as the $3 \mathrm{D}$ tool to quantitate lung architecture. Histochem Cell Biol 155:163-181.
Knust J, Ochs M, Gundersen HJG, Nyengaard JR. (2009) Stereological estimates of alveolar number and size and capillary length and surface area in mice lungs. Anat Rec 292:113-122.

Luyckx V.A., J.F. Bertram, B.M. Brenner, C. Fall, W.E. Hoy, S.E. Ozanne and B.E. Vikse. (2013) Effect of fetal and child health on kidney development and long-term risk of hypertension and kidney disease. The Lancet 382:273-83.

Ochs M, Nyengaard JR, Jung A, Knudsen L, Voigt M, Wahlers T, Richter J, Gundersen HJG. (2004a) The number of alveoli in the human lung. Am J Respir Crit Care Med 169:120-124.

Ochs M, Knudsen L, Allen L, Stumbaugh A, Levitt S, Nyengaard JR, Hawgood S. (2004b) GM-CSF mediates alveolar epithelial type II cell changes, but not emphysema- like pathology, in SP-D deficient mice. Am J Physiol (Lung Cell Mol Physiol) 287: L1333-L1341.

Ochs M. (2014) Estimating structural alterations in animal models of lung emphysema. Is there a gold standard? Ann Anat 196:26-33.

Ochs M. (2020) "And then I met Ewald Weibel". Am J Physiol (Lung Cell Mol Physiol) 319: L403-L407.

Sterio D.C. (1984) The unbiased estimation of number and sizes of arbitrary particles using the disector. J Microsc 134:127-136.

Wulfsohn D, Knust J, Ochs M, Nyengaard JR, Gundersen HJG. (2010) Stereological estimation of the total number of ventilatory units in mice lungs. J Microsc 238:75-89. 